Discussion Papers of the

Max Planck Institute for

Research on Collective Goods

2020/18

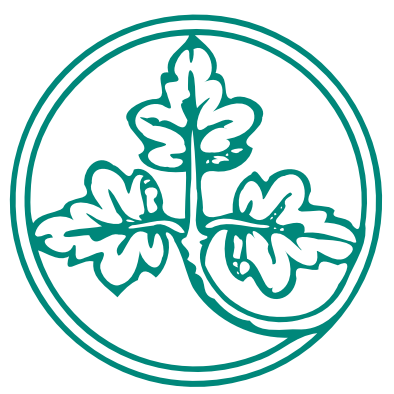

The Influence of Self and Social Image Concerns on Lying

Zvonimir Bašić

Simone Quercia 


\section{The Influence of Self and Social Image Concerns on Lying}

Zvonimir Bašić / Simone Quercia

August 2020

Revised: March 2022 


\title{
The Influence of Self and Social Image Concerns on Lying*
}

\author{
Zvonimir Bašić ${ }^{\dagger 1}$ and Simone Quercia ${ }^{2}$ \\ ${ }^{1}$ Max Planck Institute for Research on Collective Goods, Bonn, Germany \\ ${ }^{2}$ University of Verona, Verona, Italy
}

March 3, 2022

\begin{abstract}
We investigate the influence of self and social image concerns as potential sources of lying costs across two studies $(n=991)$. In Experiment 1 , in a standard die-rolling paradigm, we exogenously manipulate self-awareness and observability, which direct the focus of a person on their private and public selves, respectively. We find that our self-awareness manipulation has no effect on overreporting in comparison to a control treatment, while our observability manipulation significantly decreases reports. In Experiment 2, we introduce a design that allows to compare the effects of self and social image concerns by directing the focus either on oneself or on an external observer while keeping constant the set of observers and their information. In line with the results from Experiment 1, people lie significantly less when their focus is on the external observer rather than on themselves.
\end{abstract}

Keywords: truth-telling, lying, private information, self-image concerns, social image concerns JEL Classification: C91, D63, D82, D91

\footnotetext{
${ }^{*}$ We thank Johannes Abeler, Stefania Bortolotti, Armin Falk, Agne Kajackaite, Sebastian Kube, Daniele Nosenzo, Matthias Praxmarer, Matthias Sutter, Stefan Trautmann, Eugenio Verrina, and Matthias Wibral as well as workshop and conference participants at Lund University, Maastricht University, University of East Anglia, Humboldt University, and the Vienna University of Economics and Business for helpful comments. We gratefully acknowledge financial support from Leibniz Programme of the German Research Foundation (DFG), Institute on Behavior and Inequality (briq), and Max Planck Institute for Research on Collective Goods. The authors declare no competing interests.

${ }^{\dagger}$ E-mail addresses: basic@coll.mpg.de (Zvonimir Bašić), simone.quercia@univr.it (Simone Quercia).
} 


\section{Introduction}

In recent years, a considerable number of studies have shown that people experience psychological lying costs as they refrain from lying even when this increases their payoff (e.g., Gneezy, 2005; Shalvi et al., 2011a; Fischbacher and Föllmi-Heusi, 2013; Abeler et al., 2014; Gächter and Schulz, 2016). This sparked great interest, as it offers insights on why people avoid certain behaviors which are strongly detrimental to the functioning of societies, such as fraud or tax evasion. In this study, we investigate whether lying costs are influenced by two common and pervasive behavioral motives, self and social image concerns. While self-image concerns, in the context of lying, refer to the desire to think of oneself as an honest person, social image concerns refer to the desire to appear honest in the eyes of others. ${ }^{1}$

To study the influence of these two notions of image concerns on lying we conduct two experiments. In Experiment 1, we vary self and social image concerns by exogenously manipulating self-awareness and observability, which direct the subjects' focus on their private and public selves, respectively. To manipulate self-awareness, we expose subjects to a real-time video of their face on the computer screen, i.e., we expose them to their "self-image", as in Falk (2021). To manipulate observability, we expose subjects to a real-time video of another subject sitting in the lab, who also sees them and their decision screen through a real-time video. Subjects play a die-rolling game (Fischbacher and Föllmi-Heusi, 2013), where they roll a die in private and report the outcome on their computer, with higher reports implying higher payoff. We find that in comparison to a control treatment, where subjects see a neutral pre-recorded video, the manipulation of self-awareness successfully heightens subjects' self-focus but has no effect on the average reported die-roll outcome. On the other hand, we show that the increase of observability significantly decreases the average reported outcome, despite the fact that information about the die-roll outcome is held private. Thus, we find no evidence supporting self-image concerns as a source of lying costs through a manipulation of self-awareness, but we find causal evidence for the relevance of social image costs. To complement our social image finding, we conduct a survey where we show that the likelihood of being perceived as a liar increases with the reported outcome. Furthermore, we find that

\footnotetext{
${ }^{1}$ Social image (reputation) value can be instrumental, e.g., people might want to be perceived as honest to be treated better in the future, or direct, where people gain utility of being perceived in a positive manner, e.g., as somebody who is honest or more generally who is not an immoral person (see Bénabou and Tirole, 2006).
} 
survey respondents interpret high reports as signals for additional undesirable traits in several domains. This sheds light on the mechanisms behind our social image finding, as it indicates that subjects may expect adverse inferences from observers when reporting high outcomes, which is crucial for the social image channel to operate.

One limitation of Experiment 1 is that it does not allow a direct comparison between the two image treatments. In particular, while in the social image treatment we introduce a new observer, in the self-image treatment we make the existing observer (the subject themselves) more salient. In Experiment 2, we address this issue by designing a new experiment that allows us to draw inferences on the relative importance of the two motives. To do this, we keep constant the set of observers as well as the information observers receive across the self and social image treatments, but only manipulate the salience of the two image domains. In both treatments, subjects enter an online 1-to-1 video call with the experimenter. Their task is to roll a virtual die in private and report the outcome to the experimenter via chat. Participants are fully aware that the experimenter observes them during the entire video call but does not observe the outcome of the die roll. Our treatment manipulation varies whom the participants see on the screen. In the Social-Call treatment, subjects see the experimenter on their screen, while in the Self-Call treatment subjects see themselves on the screen. We find that making the experimenter salient in contrast to making the subject salient significantly decreases overreporting. This finding complements our results from Experiment 1. Together, the results favor social image concerns as a motive bearing stronger potential to reduce lying behavior than self-image concerns.

Our study offers several contributions to the literature on lying costs. First, it contributes to the discussion on the relevance of self-image concerns in lying situations. Numerous studies have suggested self-image as a potential source of lying costs; however, the empirical evidence is mostly indirect (Shalvi et al., 2011a; Fischbacher and Föllmi-Heusi, 2013). We provide a direct manipulation of self-image building on the recent work of Bénabou et al. (2020), which posits that self-image concerns arise from the awareness of discrepancy between internal standards of behavior and the self (e.g., in light of current behavior). To make self-image concerns salient, we manipulate one's self-awareness, increasing the awareness of the aforementioned discrepancy and, ceteris paribus, self-image costs. ${ }^{2}$ While we find that subjects become more

\footnotetext{
${ }^{2}$ This reasoning dates back to objective self-awareness theory by Duval and Wicklund (1972), who posit that high levels of self-awareness induce behavior driven by salient moral standards. To test this theory, the
} 
focused on their private self, we observe no significant effect on reports. Hence, through our self-awareness manipulation, we do not find support for the hypothesis that self-image concerns affect lying. This is in line with studies which also found no support for that hypothesis (Verschuere et al., 2018), or which offered alternative explanations to results that were previously explained through self-image costs, such as the existence of partial lying (Gneezy et al., 2018).

Second, our study contributes to the literature on social image concerns in lying behavior. In contrast to self-image concerns, the evidence on social image is more robust and indicates consistently that social image concerns are important drivers of lying behavior (see Gneezy et al., 2018; Abeler et al., 2019; Fries et al., 2021). However, previous studies commonly increase social image concerns by letting the experimenter observe both the state of the world (the outcome of the randomizing device) and the report. We contribute to this literature by showing that people care about social image costs even when the state of the world remains private information and just their reports are observed. ${ }^{3}$ This captures one common characteristic of naturally occurring lying situations, namely the possibility of deception. In our setup, the die-roller can try to deceive the receiver of the information regarding the true state of the world. ${ }^{4}$ We complement this result with survey evidence on the mechanisms behind the effect. Consistent with recent findings (Choshen-Hillel et al., 2020), we observe that reports are perceived as informative about others' lying behavior — which is predicted by theory (e.g., Gneezy et al., 2018; Abeler et al., 2019) — and also informative about additional traits in other domains.

Finally, to the best of our knowledge, we are the first to directly compare the relevance of self and social image concerns for lying behavior. Understanding their comparative potential in inhibiting cheating behavior can be of great interest, especially from a policy perspective.

most common manipulation has been to place a mirror in front of the subjects during the decision phase. It was used to show that increased self-awareness, for example, decreases simple transgressions (Beaman et al., 1979), increases the attribution of causality for a specific consequence to oneself (Duval and Wicklund, 1973), and can induce the use of corporal punishment depending on the subjects' inner attitudes towards it (Carver, 1975).

${ }^{3}$ Our findings support recent theoretical models which assume reputation or social image concerns as behavioral drivers. In particular, in models that do not allow downward lying, an increase in the parameter capturing reputation or social image concerns predicts a decrease in lying (see Dufwenberg and Dufwenberg, 2018; Khalmetski and Sliwka, 2019). Our results confirm this prediction.

${ }^{4}$ There are also studies that manipulate the probability with which the highest outcome occurs while not revealing the state of the world (Gneezy et al., 2018; Abeler et al., 2019). Such studies provide supporting evidence for social image costs, but can also be explained by other factors (see Abeler et al., 2019, for a discussion). 
Our findings suggest that manipulations of observability have a greater capacity of reducing lying behavior and hence have higher potential for policy implementations.

The remainder of the paper is structured as follows. In Section 2, we describe the experimental design and the results of Experiment 1. In Section 3, we describe the experimental design and the results of Experiment 2. In Section 4 we summarize and conclude.

\section{Experiment 1}

In Experiment 1, we manipulate subjects' self-awareness and observability in order to increase self and social image costs, respectively. We then compare these two treatments to a control treatment.

\section{$2.1 \quad$ Experimental design}

Our experimental setup is closely based on the die-rolling paradigm of Fischbacher and FöllmiHeusi (2013). While sitting in the lab cubicles, subjects were asked to roll a six-sided die and report the outcome of the die roll on their computer. Their payoff was equal to the reported outcome minus 1 euro. As in Fischbacher and Föllmi-Heusi (2013), subjects were told to roll the die minimally twice, but to report the outcome of the first roll (for experimental instructions, see Subsection A.1 in Appendix). Subjects were rolling the die in a non-transparent plastic cup, ensuring that only they could observe the outcome. ${ }^{5}$

We designed three different treatments: Self-image, Social image, and Control. In the Self-image treatment, we exogenously manipulated self-awareness, which directs a person's focus on their private self. In order to increase self-awareness, we exposed the subjects to their own image. From the moment subjects sat in the cubicles, a camera installed on the top of the monitor was capturing the image of their face, and playing it in real time in the upper part of their computer screen (see Figures A2 and A3 in Appendix). The camera was positioned in such a way that the subjects could not evade its visual field, but also, that the plastic cup on the table was not in this field. Additionally, we used a software which automatically zoomed on subjects' faces. Subjects were informed that the video was not being recorded, and that only they were able to see it. In order to give some meaning to the camera, subjects were also informed that they would answer a few short questions on the

\footnotetext{
${ }^{5}$ The setup is similar to the die-under-cup paradigm by Shalvi et al. (2011b).
} 
camera technology and settings at the end of the experiment.

To verify that we induce higher self-awareness, immediately after subjects took their decisions, we implemented a manipulation check on a subset of our sample. It consisted of a sentence completion task (Exner, 1973), commonly used in the psychology literature to estimate one's self-awareness (see Carver and Scheier, 1978). In particular, the task measures self-focus, which is indicative of self-awareness. It consists of 30 sentences which subjects have to complete. ${ }^{6}$ Following Exner (1973), two research assistants independently coded the answers based on four categories: self-focused, external world focused, ambivalent or neutral answer. The answers were then assigned to a category only if both research assistants agreed on the category ( $73 \%$ of all answers). After the manipulation check, the cameras were turned off, and the subjects answered a short questionnaire comprising questions on sociodemographics, the camera, and Big 5 personality traits (Costa and McCrae, 1992).

In the Social image treatment, we exogenously manipulated observability by exposing subjects to the observation of other participants, i.e., observers. Upon their arrival at the lab, subjects were randomly assigned one of two roles, decision-makers or observers. Decisionmakers were facing identical procedures as in Self-image, but instead of viewing their face, they saw the face of their observer in real time. Observers were also seated in private cubicles as the decision-makers, but had no decisions to make. Each observer was paired with one decision-maker, and they saw i) the video of their paired subject's face in real time, and ii) their paired subject's decision screen in real time. This was common knowledge. The procedure made observers aware of the report, but not of the actual die-roll outcome. ${ }^{7}$

To design a comparable Control treatment, we address two concerns. First, subjects in both of our treatments were exposed to a video. If such a distraction drains cognitive resources, subjects could act affectively, potentially biasing the results. ${ }^{8}$ Second, in both treatments subjects saw a person looking at them (either the observer or themselves). Several

\footnotetext{
${ }^{6}$ For example, the first three sentences are: "I think...", "I was happiest when...", and "It's fun to daydream about..." (for the list of all sentences see Subsection A.3 in Appendix).

${ }^{7}$ Alongside the questionnaire from Self-image, decision-makers were also asked if they had ever seen their observer before, and if so, what was their relationship with them. Only one subject indicated knowing the paired observer. Removing this subject from the data does not change our results.

${ }^{8}$ Dishonest behavior has been considered a cognitively demanding process linked to brain areas responsible for cognitive control (Sip et al., 2008; Greene and Paxton, 2009). On the one hand, studies show that when cognitive control is low due to cognitive depletion, people's automatic response is to act more selfishly (Achtziger et al., 2015), and more dishonestly (Gino et al., 2011), which could bias our results upwards. On the other hand, other studies suggest that people's automatic response is to behave more prosocially (Rand et al., 2012; Schulz et al., 2014). If subjects care about how much money the experimenter is left with, or if prosociality as a positive trait is connected to honesty, this could bias our results downwards.
} 
studies have shown that being exposed to social cues such as a pair of observing eyes can influence behavior (Haley and Fessler, 2005; Bateson et al., 2006; Rigdon et al., 2009). To address these two issues, our Control treatment is identical to the other two treatments, except that instead of seeing their own or the observer's face, subjects saw a mute video footage of a famous German news presenter (see Figure A4 in Appendix). As the context of the video was immediately recognizable, the subjects were perfectly aware that the video was prerecorded. Moreover, the news presenter is a non-controversial public person working for a mainstream public service, and as such does not trigger tendentious associations. ${ }^{9}$

The lying task lasted less than 10 minutes and it was run after another task in line with Fischbacher and Föllmi-Heusi (2013). In the preceding task, subjects were exposed to the same treatment manipulation as in the subsequent die-rolling experiment. ${ }^{10}$ Hence, the cameras were not abruptly turned on when reaching the lying task. 685 subjects participated in the experiment ( $59.7 \%$ female), out of which 531 subjects participated as decision-makers and 154 as observers. Observers earned 8 euros for their participation. Decision-makers were not informed about the observers' payoff to avoid influences driven by social comparison, e.g., inequity considerations (Fehr and Schmidt, 1999). Subjects were primarily students of the University of Bonn and were recruited with hroot (Bock et al., 2014). Sessions were conducted at the BonnEconLab in February 2016 and July 2017. The sentence completion task (manipulation check) was conducted only with subjects that participated in July 2017. Each session was dedicated to one treatment, and treatments were balanced within and across days of conduction. The experiment was programmed using Z-Tree (Fischbacher, 2007), and it follows ethical guidelines for study procedures from the BonnEconLab, University of Bonn.

\subsection{Results}

We start by analyzing the difference between Control and Self-image. We first look at the manipulation check and inspect whether our self-image manipulation had an effect on subjects' self-focus. We calculate the frequency of self-focused answers for each individual and find that the average frequency is $43.05 \%$ in Control and $46.32 \%$ in Self-image. This is a

\footnotetext{
${ }^{9}$ Comparing Self or Social image treatment with the Control treatment ensures that any difference can be interpreted as the effect of increased self-awareness or observability, respectively, as any potential effects of social cues or cognitive depletion would be present in all three treatments. Notice, furthermore, that Falk (2021) uses an identical control treatment in an investigation of self-image concerns for moral behavior and compares it with a control treatment without any video, finding no difference between the two.

${ }^{10}$ In the preceding task, subjects played a dictator game.
} 
statistically significant difference (two-sided t-test, $p=0.017$ ) with an effect size of 0.351 standard deviations. Hence, we find that our manipulation induces an increase in subjects' self-focus. ${ }^{11}$
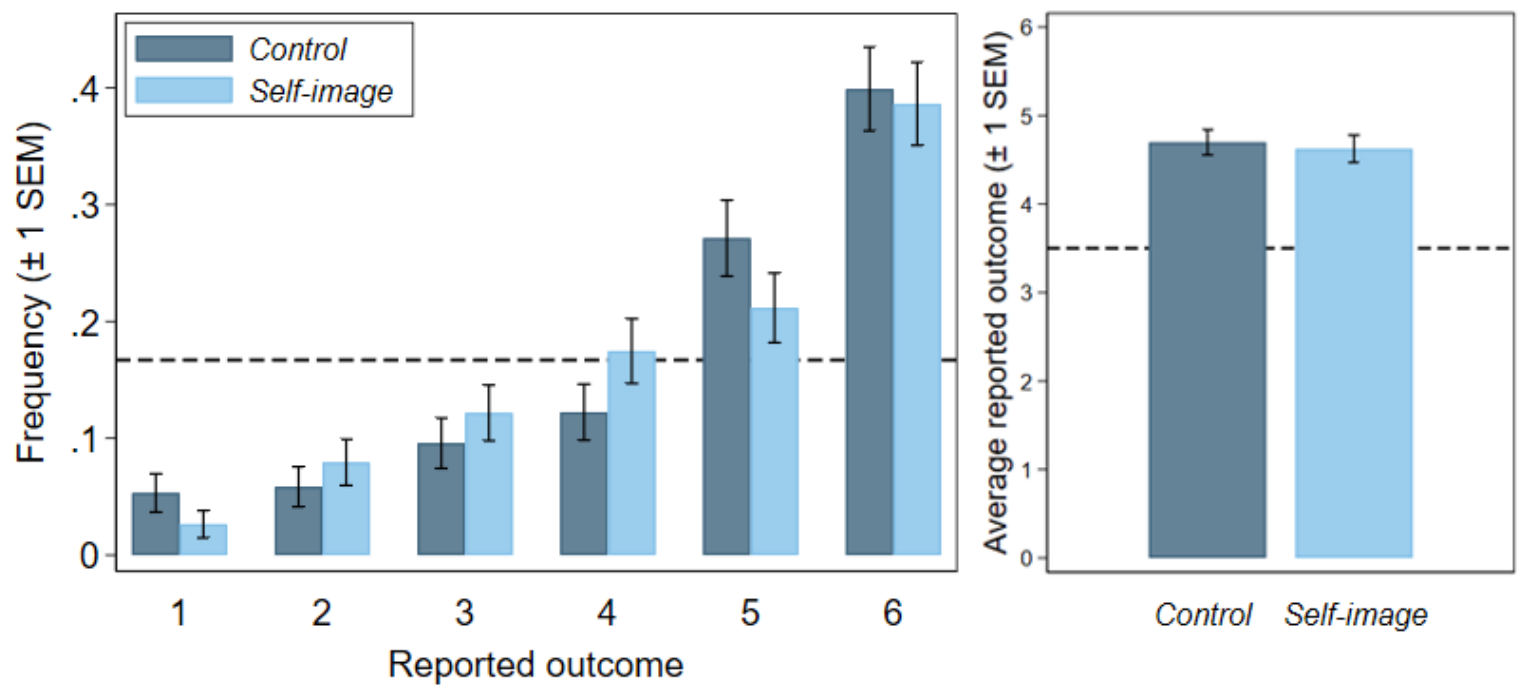

Figure 1: Frequencies of each reported outcome (left panel) and the average reported outcome (right panel) in Self-image and Control. Error bars indicate standard error of the means. The dashed line represents the expected frequency of each outcome (left panel) and the expected average outcome (right panel).

Next, we focus on the reports from the die-rolling game. To check whether people overreport the true outcome, we contrast the reports of the die rolls with the uniform distribution by applying the Kolmogorov-Smirnov test for discrete data (henceforth KS $d$, Jann et al., 2008). In Figure 1, we report the frequency of each reported outcome (left panel) and the average reported outcome (right panel) in Control $(n=188)$ and Self-image $(n=189)$. We find that the distribution of reports is significantly different from the uniform distribution in both treatments (two-sided KS $d$ tests, $p<0.001$ for both treatments). Next, we compare the average reports between the two treatments. Figure 1 (right panel) shows that people report on average 4.62 in Self-image and 4.70 in Control with no significant differences across the two (two-sided t-test, $p=0.630$ ). The result remains insignificant if we perform the analysis using an OLS regression $(p=0.630)$ and when including control variables $(p=0.681$, see Table A1 in Appendix).

\footnotetext{
${ }^{11}$ For purposes of robustness, we also compare the frequencies of external-world focused answers and ambivalent answers across the two treatments and find no significant difference (two-sided t-tests, $p>0.346$ for
} 

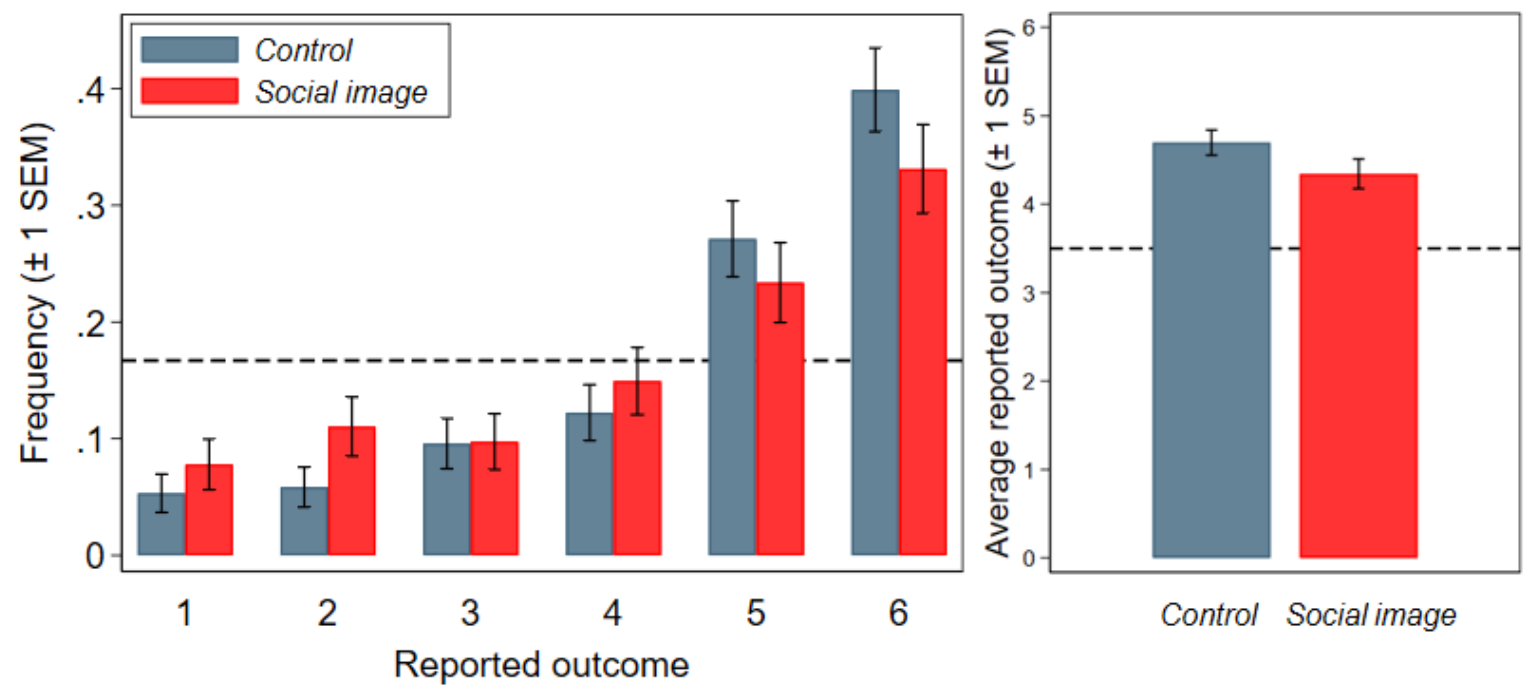

Figure 2: Frequencies of each reported outcome (left panel) and the average reported outcome (right panel) in Social image and Control. Error bars indicate standard error of the means. The dashed line represents the expected frequency of each outcome (left panel) and the expected average outcome (right panel).

Next, we analyze the difference between Control $(n=188)$ and Social image $(n=154)$. In Figure 2 we report the frequency of each reported outcome (left panel) and the average reported outcome (right panel) in the two treatments. Similarly to Control and Self-image, subjects in Social image significantly overreport their outcome compared to the uniform distribution (two-sided KS $d$ test, $p<0.001$ ). However, as shown in Figure 2 (right panel), people on average report less in Social image (4.34) than they do in Control (4.70). This difference is statistically significant (two-sided t-test, $p=0.038$ ). We further test the robustness of this effect in an OLS regression. The result remains robust when using an OLS regression $(p=0.040)$ and when adding control variables (at a $10 \%$ level, $p=0.059$, see Table A1 in Appendix).

\subsection{Survey evidence on social image costs}

So far, we have shown that people do not significantly react to an increase in self-awareness but they do so to an increase in observability. To further support the findings in our Social image treatment, we report results from a survey ran on a separate set of 100 subjects where both categories). 
we explore whether people i) perceive that high reports are more likely to be a lie and ii) attribute negative traits to subjects who report high numbers. ${ }^{12}$ These questions are relevant in understanding reputation effects which can come from reports. For die-rollers' social image to be at stake, it is necessary that reports alone (as outcomes are private) are perceived as informative signals. In the survey, subjects were informed about the die-rolling paradigm and were asked to evaluate the probability of a subject being a liar conditional on each of the 6 reports. Moreover, for hypothetical reports they were confronted with 6 different statements. For each of the statements they had to indicate how much they agreed on a scale from 0 to 7. The statements were: "I find this person trustworthy", "I would accept this person as a flatmate in my shared flat", "I would lend money to this person", "I would employ this person", "I would buy a car from this person", and "I would vote for this person". The hypothetical reports differed within-subject across the six statements, and the order of the hypothetical reports was randomized between-subject. The survey was conducted with students in front of the University of Bonn library and canteen. Each participant earned 5 euros for participating.

We find that the average belief about the probability that subject is a liar increases with the report (OLS regression with standard errors clustered at the individual level, $p<0.001$, see Figure A5, left panel in Appendix). With respect to the agreement with the statements, we observe that on average, survey participants perceive a person reporting higher numbers as less trustworthy, and they declare to be less willing to consider such a person as a flatmate, to lend them money, employ them, buy a car from them, or vote for them (Spearman's rho, $p=0.004$ for "Flatmate" comparison, $p<0.001$ for all other comparisons, see Figure A5, right panel in Appendix).

\subsection{Discussion}

To summarize, while we find that higher self-awareness has no significant effect on the reported outcomes, increasing observability significantly decreases the reported outcomes. One

\footnotetext{
${ }^{12}$ We opted to elicit the survey on a separate set of subjects for several reasons. Running the survey with subjects from Experiment 1 would induce a motivated reasoning issue, where subjects reporting high number might want to justify to themselves (or the experimenter) that such a report is not perceived as negative. Moreover, perceptions of whether a person is a liar could also potentially be correlated with some other drivers of lying behavior, e.g., intrinsic lying costs or one's level of concern for social image. The individuallevel relation between one's lying behavior and such perceptions would be confounded in such a case. Apart from avoiding these potential confounds, showing the finding with a separate set of subjects also offers some external validity, as it suggests that the negative view on high reports is a more general finding, and not only tied to our sample in the die-rolling experiment.
} 
important limitation of Experiment 1 is that it does not allow a direct comparison between the two image treatments. The reason is that while in the Social image treatment we increase social image concerns by introducing a new observer, in the Self-image treatment we increase self-image concerns by making the existing observer, i.e., the subject themselves, more salient. The aim of the next section is to tackle this limitation and present a design which renders a comparison between the two image components possible.

\section{Experiment 2}

In Experiment 2, we maintain constant across treatments the set of the observers as well as the information the observers receive. In order to contrast self and social image concerns, we just manipulate the salience of self or social image.

\subsection{Experimental design}

Similarly to Experiment 1, Experiment 2 also builds on the Fischbacher and Föllmi-Heusi (2013) paradigm, but it consists of 1-on-1 online video call sessions between an experimenter and a subject. A day before their session slot, subjects received a link for the call in an email. Together with the link, subjects were also explicitly instructed that the call will be with an experimenter. They were informed to turn on the camera during the session and to be in its visual field so that the experimenter could see them. Moreover, they were instructed not to use the microphone and to report their decisions via the chat of the video call. They were also explicitly instructed to maximize the video call window over their screen. ${ }^{13}$ Immediately after joining the call, the experimenter sent experimental instructions to the subject through the chat. The experimenter did not use the microphone. ${ }^{14}$ The instructions informed the subject that their task was to roll a virtual six-sided die and to report the outcome via chat (for experimental instructions, see Subsection A.2 in Appendix). To roll a virtual die, subjects had to use a mobile phone or a tablet and type in "roll a die" in the Google search engine. The engine would then roll a virtual six-sided die. Subjects were instructed to make sure that only they can see the mobile or the tablet screen, ensuring that the die-roll outcome

\footnotetext{
${ }^{13}$ Minimizing the video call window would have removed the chat function, preventing them from reporting their decision. The subjects were thus not able to minimize the video while making the decision.

${ }^{14}$ The experimenter would only intervene verbally if there were technical issues, or if the subject did not respond to instructions in the chat. We control for this in our regression analysis.
} 
remains private. Their payoff was equal to their reported outcome multiplied by 0.5 euros. The call lasted on average 5 minutes. Before exiting the call, subjects received a link for a short questionnaire via chat.

We designed two symmetric treatments. In the Self-Call treatment, from the moment subjects joined the call until the call was finished, subjects saw themselves in a large format on the screen (see Figure A6 in Appendix). This was achieved using the share screen function by the experimenter, who was sharing the screen they would see in the call, i.e., the video of the participant. In contrast, in the Social-Call treatment, subjects saw the experimenter in a large format on the screen (see Figure A7 in Appendix). In this case we used a standard video call without screen sharing. Subjects were additionally informed through the instructions that they will be seeing themselves on the screen (in Self-Call), or the experimenter (in Social-Call), throughout the call. The respective video dominated the screen, while the chat function was situated on the right of the video. ${ }^{15}$ The experimenter was a research assistant of similar age as the subjects.

The design shares similar design features with Experiment 1, with one important difference. Only the experimenter and the subject are the present observers in both treatments and the information they receive concerning the outcome and the report is held constant across treatments. The two treatments only manipulate subjects' focus between the two observers.

Altogether, 306 subjects participated in the two treatments $\left(58.7 \%\right.$ female) ${ }^{16}$ In addition to the earnings from the die-roll task, subjects also earned a show-up fee of 2 euros. Subjects were primarily students of the University of Bonn and were recruited with hroot (Bock et al., 2014). Sessions were conducted from July to September 2021. The treatment assignment was always balanced within and across days of implementation. We used Microsoft Teams for the video calls and Qualtrics for the subsequent survey. Subjects participated in the call through their web browser. The study was carried out in accordance with the IRB block approval granted by the Ethics Council of the Max Planck Society (Application No. 2018_3).

\footnotetext{
${ }^{15}$ In both treatments, subjects also saw who is participating in the call in a very small format, in the lower right corner. This is a fixed feature of the video call software. In both treatments they saw their "self-view", i.e., they saw a small format video of themselves, and in the Self-Call treatment, where the experimenter had the camera turned off, subjects additionally saw that the experimenter is participating in the call, which was indicated by the shortened initials of the Lab responsible for the study.

${ }^{16}$ We excluded 41 subjects as they were not able to turn on the camera during the decision making process (25 subjects), had a major technical or procedural error (4 subjects), or did not follow the instructions, e.g., subjects who made additional reports after the first one (12 subjects). Our results remain robust when including these subjects in the analysis.
} 


\subsection{Results}

We compare the reports across Self-Call $(n=155)$ and Social-Call $(n=151)$. We first look at whether people overreport the outcome of die-rolling. In Figure 3, we report the frequency of each reported outcome (left panel) and the average reported outcome (right panel) in the two treatments. As expected, the distributions of reports in both treatments are significantly different from the uniform distribution (two-sided KS $d$ test, $p<0.001$ for both treatments). We next turn to the comparison of average reports between the two treatments (Figure 3, right panel). We find that subjects on average report 4.40 in Self-Call and 3.99 in SocialCall, which is a statistically significant difference (two-sided t-test, $p=0.021$ ). The result also remains significant when performing the analysis with an OLS regression $(p=0.021)$ and when including control variables ( $p=0.011$, see Table A2 in Appendix).

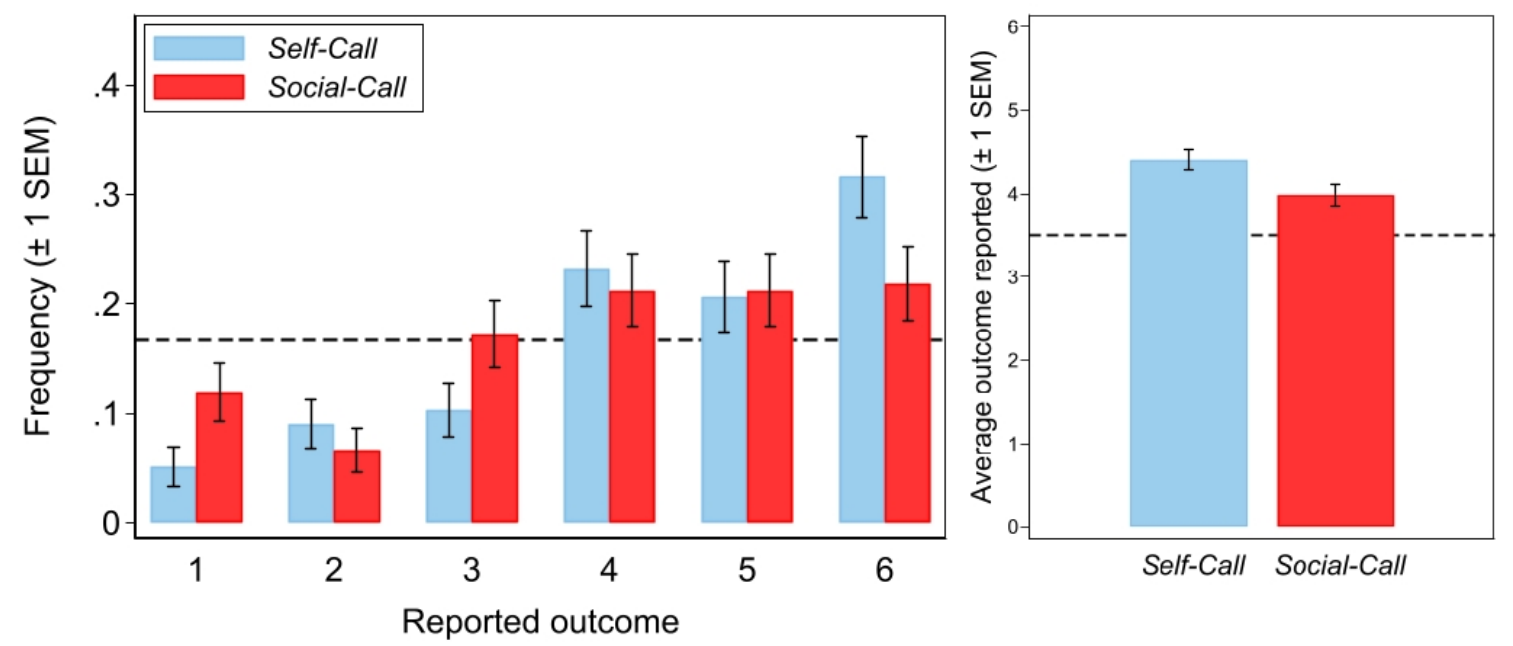

Figure 3: Frequencies of each reported outcome (left panel) and the average reported outcome (right panel) in Self-Call and Social-Call. Error bars indicate standard error of the means. The dashed line represents the expected frequency of each outcome (left panel) and the expected average outcome (right panel).

\section{Summary and conclusion}

In this paper, we have investigated the influence of self and social image concerns on lying. In Experiment 1, we have exogenously manipulated self-awareness and observability by exposing subjects to their own image or to the observation of another participant in real time, respec- 
tively. In a die-roll game, we have shown that an increase in self-awareness has no effect on the average report, although our manipulation successfully increases subjects' self-focus. In contrast, manipulating observability, while maintaining the outcome private, decreases subjects' reports. We have further supported the latter finding by showing that those who report higher numbers are more likely to be seen as liars or as having negative characteristics. In Experiment 2, we have designed a new paradigm to contrast self and social image concerns directly. Across treatments, we have kept constant the set of observers (the experimenter and the participant) as well as the information they receive, but we have manipulated which observer is made salient through their video image. We have found that shifting the focus of the subjects from themselves to the experimenter significantly decreases their reports.

Our findings contribute to a better understanding of self and social image concerns as potential lying costs. They connect to recent theoretical models, which have postulated social image concerns and (some of them) self-image concerns as sources of lying costs (Abeler et al., 2019; Gneezy et al., 2018; Dufwenberg and Dufwenberg, 2018; Khalmetski and Sliwka, 2019). Through our manipulations of observability and self-awareness, we find evidence for social image costs and fail to find evidence for self-image costs. There could be several reasons for the latter result. One is that self-image concerns might be low in certain domains. Falk (2021) and Bašić et al. (2020) also make self-image concerns salient by manipulating subjects' selfawareness and show that this increases moral and prosocial behavior. If the act of lying causes a negligible cost for one's self-image, making this cost more salient through self-awareness could have little scope to affect behavior. Alternatively, self-image concerns could be an important determinant of lying behavior, but in the die-rolling task, where the only "victim" is the experimenter and thus the negative externality is small, self-image costs could be very low. Finally, while we have detected an increase in self-focus, and similar manipulations were successful in affecting other types of behavior (Falk, 2021; Bašić et al., 2020), we also acknowledge the possibility that our manipulation might not have caused a sufficient increase of self-image concerns in order to affect lying behavior. Studying whether lying can be affected by self-awareness manipulations in situations with stronger negative externalities or designing alternative manipulations of self-image concerns could be an interesting avenue for future research.

Our results also offer novel insights on the empirical comparison of the two motives 
and on their potential from a policy perspective. In light of our results, policies targeting observability as a way to curtail cheating seem to have higher potential than policies triggering self-awareness. Our results also indicate that being observed has an impact even if one's cheating behavior is not verifiable. This finding is promising, as verifying one's actions is often very costly, while increasing the feeling of observation and scrutiny of one's reports could be achieved in a more feasible and cost-effective manner. 


\section{References}

Abeler, J., Becker, A., and Falk, A. (2014). Representative evidence on lying costs. Journal of Public Economics, 113:96-104.

Abeler, J., Nosenzo, D., and Raymond, C. (2019). Preferences for truth-telling. Econometrica, 87(4):1115-1153.

Achtziger, A., Alós-Ferrer, C., and Wagner, A. K. (2015). Money, depletion, and prosociality in the dictator game. Journal of Neuroscience, Psychology, and Economics, 8(1):1-14.

Bateson, M., Nettle, D., and Roberts, G. (2006). Cues of being watched enhance cooperation in a real-world setting. Biology Letters, 2(3):412-414.

Bašić, Z., Falk, A., and Quercia, S. (2020). Self-image, social image and prosocial behavior. Mimeo.

Beaman, A. L., Klentz, B., Diener, E., and Svanum, S. (1979). Self-awareness and transgression in children: Two field studies. Journal of Personality and Social Psychology, 37(10):1835-1846.

Bénabou, R., Falk, A., and Tirole, J. (2020). Narratives, imperatives, and moral persuasion. Working paper available at https://www.briq-institute.org/wc/files/people/arminfalk/working-papers/narratives-imperatives-and-moral-reasoning.pdf.

Bénabou, R. and Tirole, J. (2006). Incentives and prosocial behavior. The American Economic Review, 96(5):1652-1678.

Bock, O., Baetge, I., and Nicklisch, A. (2014). hroot: Hamburg registration and organization online tool. European Economic Review, 71:117-120.

Carver, C. S. (1975). Physical aggression as a function of objective self-awareness and attitudes toward punishment. Journal of Experimental Social Psychology, 11(6):510-519.

Carver, C. S. and Scheier, M. F. (1978). Self-focusing effects of dispositional selfconsciousness, mirror presence, and audience presence. Journal of Personality and Social Psychology, 36(3):324. 
Choshen-Hillel, S., Shaw, A., and Caruso, E. M. (2020). Lying to appear honest. Journal of Experimental Psychology: General, 149(9):1719.

Costa, P. T. and McCrae, R. R. (1992). Neo pi-r professional manual. Odessa, FL: Psychological assessment resources, 396:653-65.

Dufwenberg, M. and Dufwenberg, M. A. (2018). Lies in disguise - A theoretical analysis of cheating. Journal of Economic Theory, 175:248-264.

Duval, R. A. and Wicklund, S. (1972). A theory of objective self awareness. Oxford: Academic Press.

Duval, S. and Wicklund, R. A. (1973). Effects of objective self-awareness on attribution of causality. Journal of Experimental Social Psychology, 9(1):17-31.

Exner, J. J. E. (1973). The self focus sentence completion: A study of egocentricity. Journal of Personality Assessment, 37(5):437-455.

Falk, A. (2021). Facing yourself - A note on self-image. Journal of Economic Behavior \&6 Organization, 186:724-734.

Fehr, E. and Schmidt, K. M. (1999). A theory of fairness, competition, and cooperation. Quarterly Journal of Economics, 144(3):817-868.

Fischbacher, U. (2007). z-tree: Zurich toolbox for ready-made economic experiments. Experimental Economics, 10(2):171-178.

Fischbacher, U. and Föllmi-Heusi, F. (2013). Lies in disguise - An experimental study on cheating. Journal of the European Economic Association, 11(3):525-547.

Fries, T., Gneezy, U., Kajackaite, A., and Parra, D. (2021). Observability and lying. Journal of Economic Behavior $\mathcal{E}$ Organization, 189:132-149.

Gächter, S. and Schulz, J. F. (2016). Intrinsic honesty and the prevalence of rule violations across societies. Nature, 531(7595):496-499.

Gino, F., Schweitzer, M. E., Mead, N. L., and Ariely, D. (2011). Unable to resist temptation: How self-control depletion promotes unethical behavior. Organizational Behavior and Human Decision Processes, 115(2):191-203. 
Gneezy, U. (2005). Deception: The role of consequences. The American Economic Review, 95(1):384-394.

Gneezy, U., Kajackaite, A., and Sobel, J. (2018). Lying aversion and the size of the lie. American Economic Review, 108(2):419-53.

Greene, J. D. and Paxton, J. M. (2009). Patterns of neural activity associated with honest and dishonest moral decisions. Proceedings of the National Academy of Sciences, 106(30):1250612511.

Haley, K. J. and Fessler, D. M. (2005). Nobody's watching?: Subtle cues affect generosity in an anonymous economic game. Evolution and Human behavior, 26(3):245-256.

Jann, B. et al. (2008). Multinomial goodness-of-fit: Large-sample tests with survey design correction and exact tests for small samples. Stata Journal, 8(2):147.

Khalmetski, K. and Sliwka, D. (2019). Disguising lies - Image concerns and partial lying in cheating games. American Economic Journal: Microeconomics, 11(4):79-110.

Rand, D. G., Greene, J. D., and Nowak, M. A. (2012). Spontaneous giving and calculated greed. Nature, 489(7416):427-430.

Rigdon, M., Ishii, K., Watabe, M., and Kitayama, S. (2009). Minimal social cues in the dictator game. Journal of Economic Psychology, 30(3):358-367.

Schulz, J. F., Fischbacher, U., Thöni, C., and Utikal, V. (2014). Affect and fairness: Dictator games under cognitive load. Journal of Economic Psychology, 41:77-87.

Shalvi, S., Dana, J., Handgraaf, M. J., and De Dreu, C. K. (2011a). Justified ethicality: Observing desired counterfactuals modifies ethical perceptions and behavior. Organizational Behavior and Human Decision Processes, 115(2):181-190.

Shalvi, S., Handgraaf, M. J., and De Dreu, C. K. (2011b). Ethical manoeuvring: Why people avoid both major and minor lies. British Journal of Management, 22(s1):S16-S27.

Sip, K. E., Roepstorff, A., McGregor, W., and Frith, C. D. (2008). Detecting deception: The scope and limits. Trends in Cognitive Sciences, 12(2):48-53. 
Verschuere, B., Meijer, E. H., Jim, A., Hoogesteyn, K., Orthey, R., McCarthy, R. J., Skowronski, J. J., Acar, O. A., Aczel, B., Bakos, B. E., et al. (2018). Registered replication report on Mazar, Amir, and Ariely (2008). Advances in Methods and Practices in Psychological Science, 1(3):299-317. 


\section{A Appendix}

The following two subsections contain experimental instructions translated from German.

\section{A.1 Experimental instructions for Experiment 1}

\section{A.1.1 Die-roller: Control, Self-image, and Social image treatments}

The general instructions and the instructions for the first task were printed and left in front of the subjects' computer screens before they entered the lab. At the beginning of the experiment, the instructions were read out loud by one of the experimenters.

Welcome to this study!

You are participating in an economic study. Depending on your answers, you can earn a certain amount of money. The money will be paid out at the end of the study in cash. It is therefore very important that you read the instructions carefully, and that you understand them.

Only for the Control treatment. As you can see, there is a video playing on your computer screen. This video will also be played during the study.

Only for the Self-image treatment. As you can see, there is a camera installed above the computer screen. The image that the camera is capturing is shown on your computer screen in real time. Please note: No video streams are saved, and only you and no other person can see your camera video. At the end of the study we will ask you several short questions about the camera technology and camera settings.

Only for the Social image treatment. As you can see, there is a camera installed above the computer screen. You can see another participant of the study. Simultaneously, the participant can also see you. It is strictly forbidden to communicate in any way with this other participant, e.g, through waving, signs, facial expressions, or similar. This other participant has the role of observer. Your observer has received his own instructions, in which his task is clearly explained. He has only one task, and that is to observe you and your decisions. Your observer sees your computer screen in real time. That means that all the movements that you do with your mouse, and all the decisions that you 
take during this study, will be seen by your observer. Please note that there can be short delays in the transmission of the camera video. The transmission of your screen and mouse movements occurs with no delay. Please note: No video streams are saved, only your observer and no other person can see your camera video. If you disagree with this, you can finish your participation on the study now. At the end of the study, we will ask you several short questions about the camera technology and camera settings. After the end of the study, your observer will leave the laboratory before you.

All statements made in these instructions are true. This holds generally for all studies conducted at the Bonn Laboratory for Experimental Economic Research, and also for this study.

During the study, communication between participants is forbidden. If you have questions, then please direct them only to us. Please raise your hand and a member of the experimental team will come to answer privately. Violating this rule leads to exclusion from the study.

At this point, the experimenter read the instructions of the first task, which was followed by the task itself. After the task, we presented the subjects with the instructions of the die-rolling task on their computer screens.

Die roll, introductory screen. The first part of the study is now finished. The second part of the study is not connected to the first. For the following task you will require a cup and a die. Please wait until we bring it to you.

At this point, the subjects were each given a plastic non-transparent cup and a die.

Die roll, instructions screen. Please do not use the die nor the cup before you are asked to do so. When you are asked to roll the die, roll it twice. More specifically, take it with your hand and roll it in the cup. Your task is to report which number you have rolled with the first try. Depending on the reported number, you will receive a certain amount of money. How much money you earn for a given number is presented in the table underneath (see Figure A1).

The second roll is to assure yourself that the die is not loaded. You may also roll the die 


\begin{tabular}{|c|c|c|c|c|c|c|}
\hline Rolled number & 1 & 2 & 3 & 4 & 5 & 6 \\
\hline Payoff & 0 euros & 1 euro & 2 euros & 3 euros & 4 euros & 5 euros \\
\hline
\end{tabular}

Figure A1: Payment table

more than two times; however, only the first roll counts. The money that you earn in this task will be added to the money you have earned so far and paid out at the end of the study in cash.

One more time: When you are asked to roll the die, roll it twice. Report the number that you rolled with the first try. The amount of money you will earn depending on your report is presented in the table.

Please do not start yet. If you have understood everything, press "next". If you have questions, raise your hand.

Die roll, decision screen. Roll the die twice now. Report which number you have rolled with the first try.

\section{A.1.2 Observer}

The instructions were printed and left in front of the subjects' computer screens before they entered the lab.

\section{READ IMMEDIATELY}

Welcome to this study!

Important: It is strictly forbidden to communicate with the participant you see in the video in any way, e.g., through waving, signs, facial expressions, or similar.

In this study, you are participating in a role of observer. You only have one task, and 
that is to observe another participant of the study. For this task, you will receive a payment of 8 euros in cash at the end of the study.

On your screen, you can see a video of another participant and his decision screen in real time. That means that you will observe the decisions that this participant takes during the study. At the same time, this participant can also see you through the camera that is installed on your computer screen. Please note: No video streams are saved. Except for the participant you see, no other person can see the video from your camera.

During the study, communication between participants is forbidden. If you have questions, direct them to us. Raise your hand, and a member of the experimental team will come to answer privately. If you violate this rule, you will be excluded from the study.

The instructions that will be read out loud at the beginning of the study are for the subjects who will take decisions. That means, they are intended for the participant who you are observing. Listen carefully, so that you can understand what is the task of this participant. 


\section{A.2 Experimental instructions for Experiment 2}

Subjects received the experimental instructions via chat immediately after entering the video call.

Welcome!

You are participating in an economic study. You will earn 2 euros just for participation. Depending on your answers, you can earn additional money.

Only for the Self-Call treatment. During the call, you will see yourself on your screen.

Only for the Social-Call treatment. During the call, you will see the experimenter on your screen.

Your task is described in the following. Please read all the steps before starting with the task:

1. Open Google on your cell phone or tablet.

2. Type in „Roll a die“ and press enter.

3. You will see the result of a 6-sided die-roll. Make sure that only you can see the screen of your cell phone or tablet.

4. Your task is to report the result of the die roll in the chat of the video call. To do so, write "I rolled a X", where X represents the number you rolled.

5. You are going to be paid according to your reported number as follows:

You report 1

You earn $0.5 €$

You report 2

You earn $1 €$

You report 3

You earn $1.5 €$

You report 4

You earn $2 €$ 
You report 5

You earn $2.5 €$

You report 6

You earn $3 €$

Once you are ready, you can take your cell phone or tablet and start the study following the steps above. When you are finished, please wait for further instructions.

After the subjects reported their die-roll outcome, they received the link for the questionnaire. Once they loaded the questionnaire, they exited the 1-to-1 session with the experimenter. 


\section{A.3 Sentence completion task}

In the following part of the experiment your task is to complete unfinished sentences. The beginning of the sentence is given, for example: "The weather...". You have to complete the sentence on the "..." position. Please write whatever comes to your mind first, without long thinking.

1. I think...

2. I was happiest when...

3. It's fun to daydream about...

4. My father...

5. If only I could...

6. It's hardest for me...

7. I wish...

8. As a child I...

9. I am...

10. I'm at my best...

11. Others...

12. When I look in the mirror...

13. If only I would...

14. At least I'm not...

15. My sex life...

16. It upsets me when...

17. The thing I like best about myself...

18. Friends...

19. I would like most to be photographed...

20. I guess I'm...

21. My mother...

22. I wonder...

23. The worst thing about me...

24. I always wanted...

25. I try hardest to please... 
26. Someday I...

27. My appearance...

28. My parents...

29. If I had my way...

30. I like... 


\section{A.4 Additional figures and tables}

Table A1: OLS regressions estimates of treatment effects in Experiment 1

\begin{tabular}{lcc} 
Variables & \multicolumn{2}{c}{$\begin{array}{c}\text { Dependent variable: } \\
\text { reported outcome }\end{array}$} \\
\cline { 2 - 3 } Self-image & $(1)$ & $(2)$ \\
\cline { 2 - 3 } Social image & -0.072 & -0.061 \\
& $(0.150)$ & $(0.148)$ \\
Constant & $-0.353^{* *}$ & $-0.317^{*}$ \\
& $(0.171)$ & $(0.167)$ \\
Control variables & $4.697^{* * *}$ & $4.889^{* * *}$ \\
& No & $(0.359)$ \\
\hline Observations & 531 & Yes \\
R-squared & 0.009 & 0.068 \\
\hline
\end{tabular}

The table presents OLS regressions using reported outcome as the dependent variable and Control treatment as the omitted category. Control variables include age, gender, and Big 5 personality traits. Robust standard errors in parentheses, ${ }^{* * *} \mathrm{p}<0.01,{ }^{* *} \mathrm{p}<0.05$, $* \mathrm{p}<0.1$.

Table A2: OLS regressions estimates of treatment effects in Experiment 2

\begin{tabular}{lcc} 
Variables & \multicolumn{2}{c}{$\begin{array}{c}\text { Dependent variable: } \\
\text { reported outcome }\end{array}$} \\
\cline { 2 - 3 } Self-Call & $(1)$ & $(2)$ \\
& & \\
& $0.413^{* *}$ & $0.456^{* *}$ \\
Constant & $(0.178)$ & $(0.177)$ \\
& $3.987^{* * *}$ & $3.415^{* * *}$ \\
Control variables & $(0.132)$ & $(0.315)$ \\
& No & Yes \\
\hline Observations & 306 & 305 \\
R-squared & 0.017 & 0.055 \\
\hline
\end{tabular}

The table presents OLS regressions using reported outcome as the dependent variable and Social-Call as the omitted category. Control variables include age, gender, and a dummy variable indicating whether the experimenter had to verbally intervene before the report. Robust standard errors in parentheses, ${ }^{* * *} \mathrm{p}<0.01,{ }^{* *} \mathrm{p}<0.05,{ }^{*} \mathrm{p}<0.1$. 


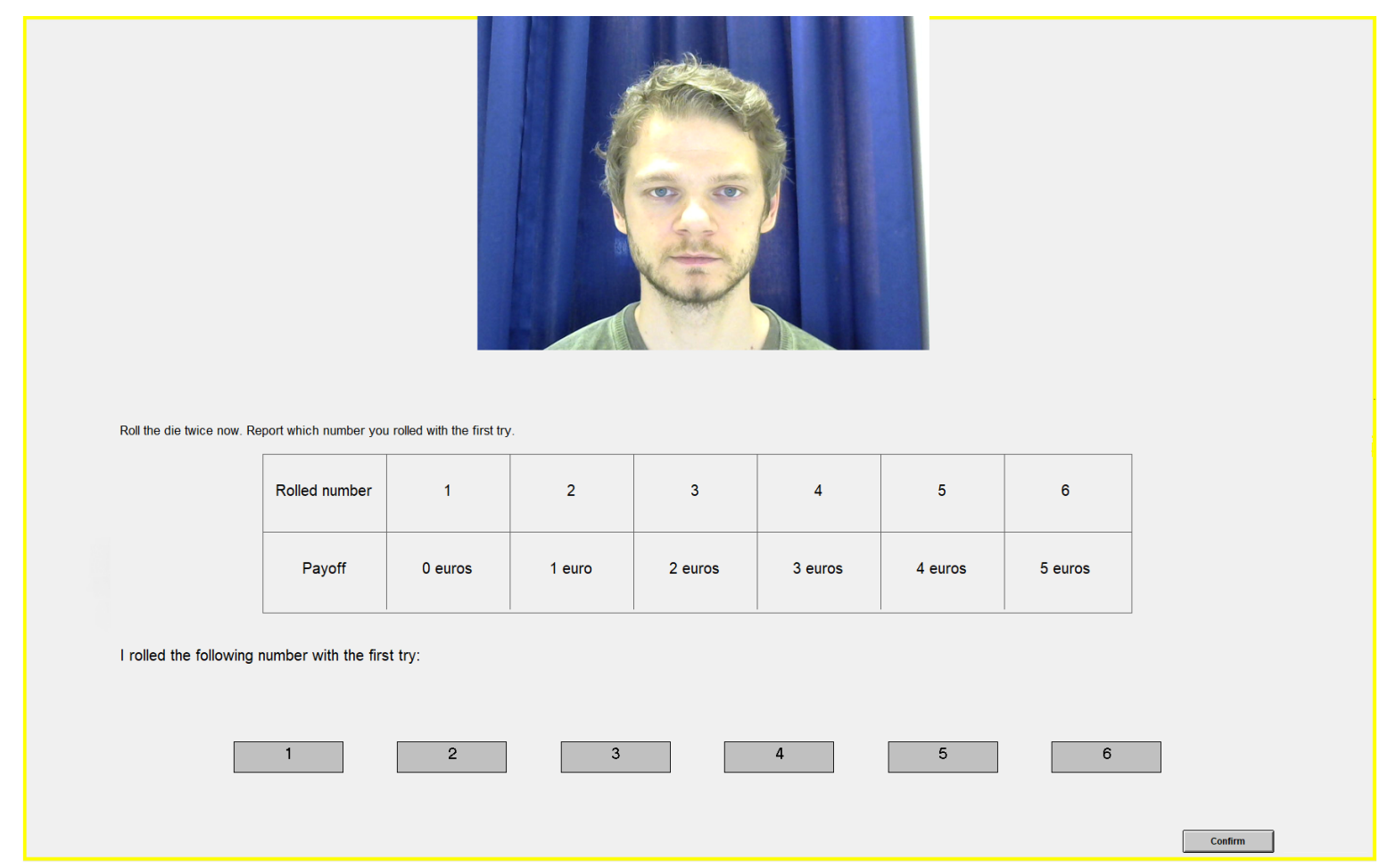

Figure A2: Decision screen in Self-image and Social image (translated from German) 


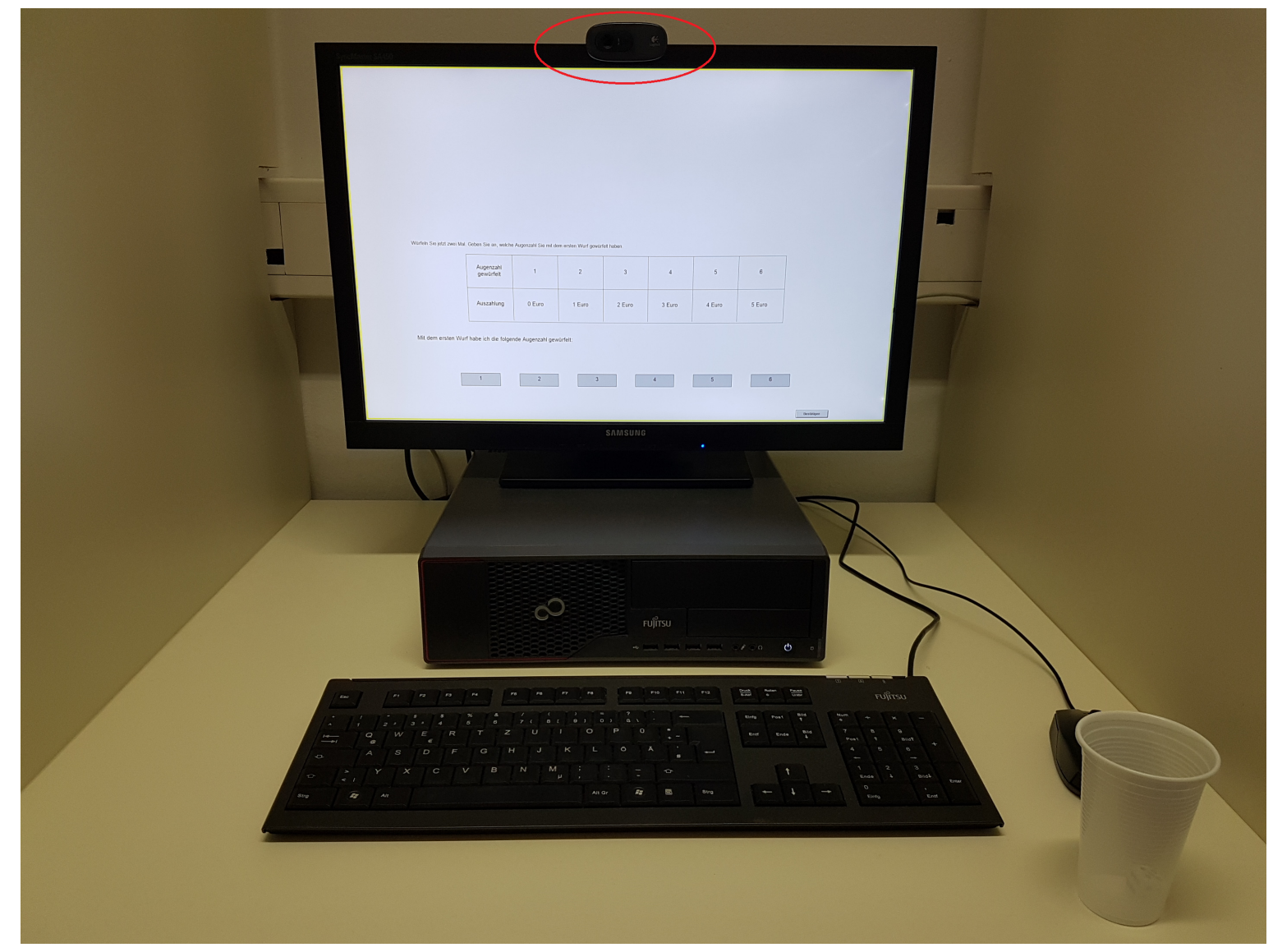

Figure A3: The cubicle in Self-image and Social image with a camera attached to the computer screen. The video is turned off for demonstration purposes. 


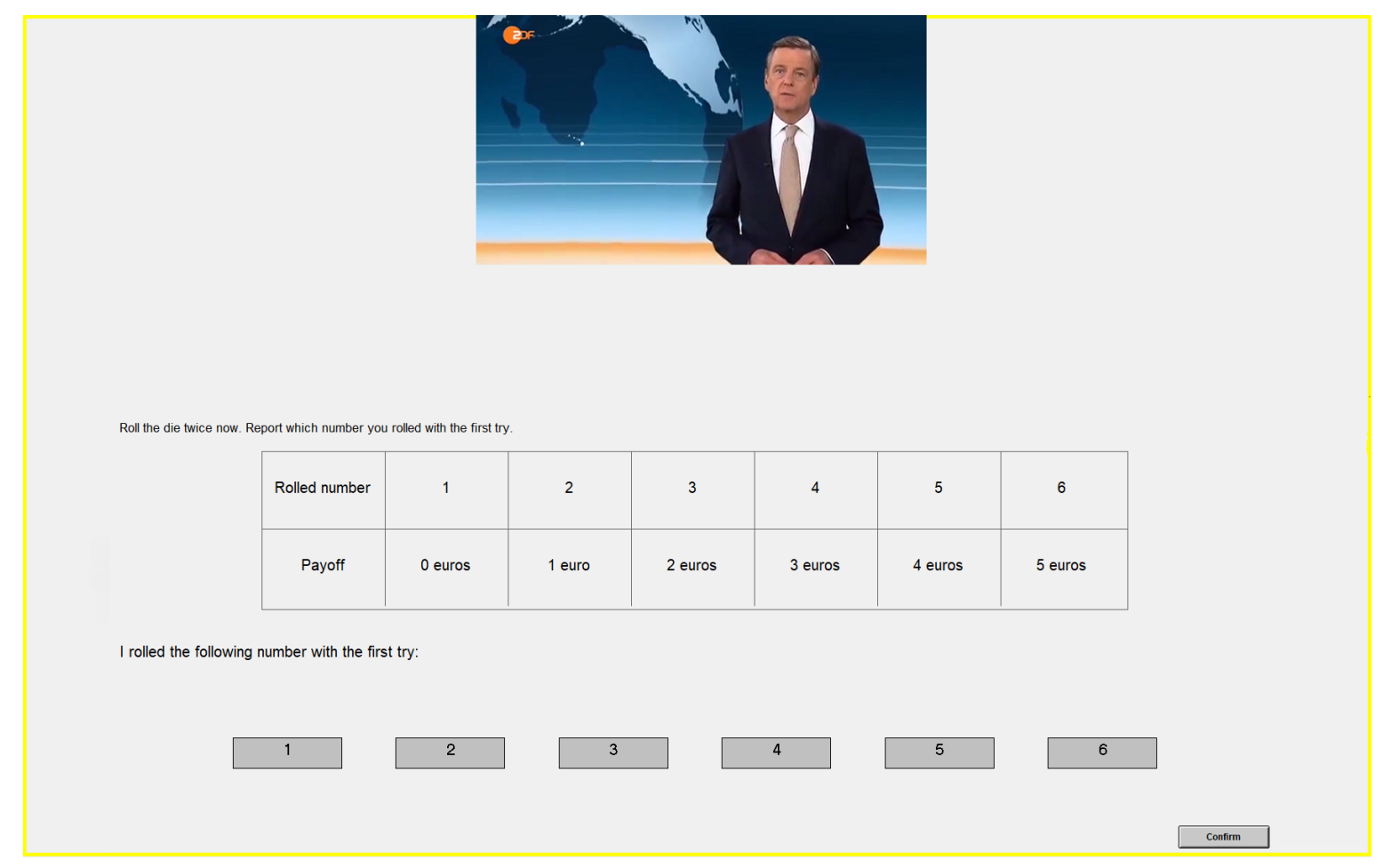

Figure A4: Decision screen in Control (translated from German) 


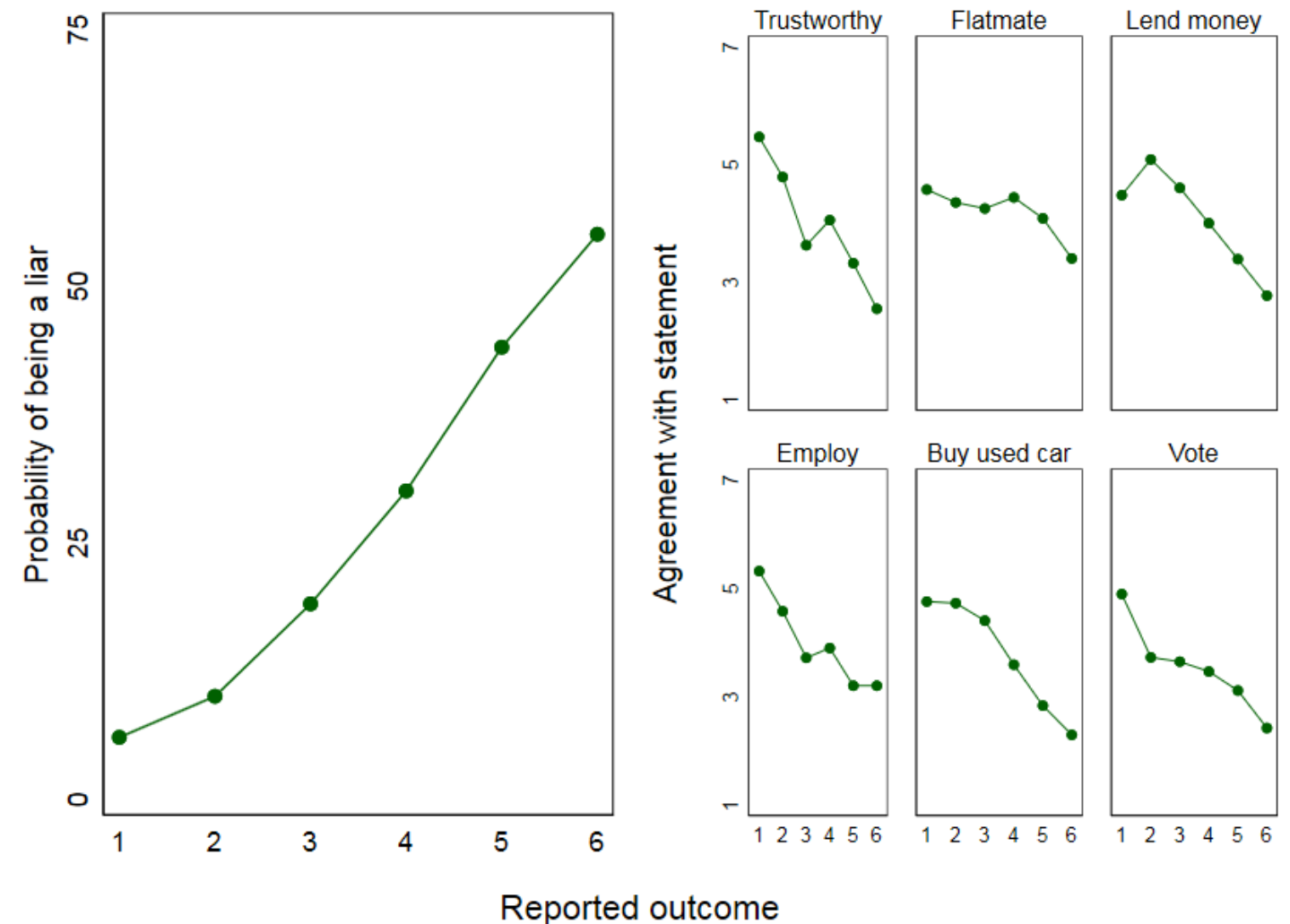

Figure A5: Survey results. The average expected probability that the subject is lying conditioning on the reported outcome (left panel), and the average agreement with the statement conditioning on the reported outcome (right panel). The statements are "I find this person trustworthy", "I would accept this person as a flatmate in my shared flat", "I would lend money to this person", "I would employ this person", "I would buy a car from this person", and "I would vote for this person". 


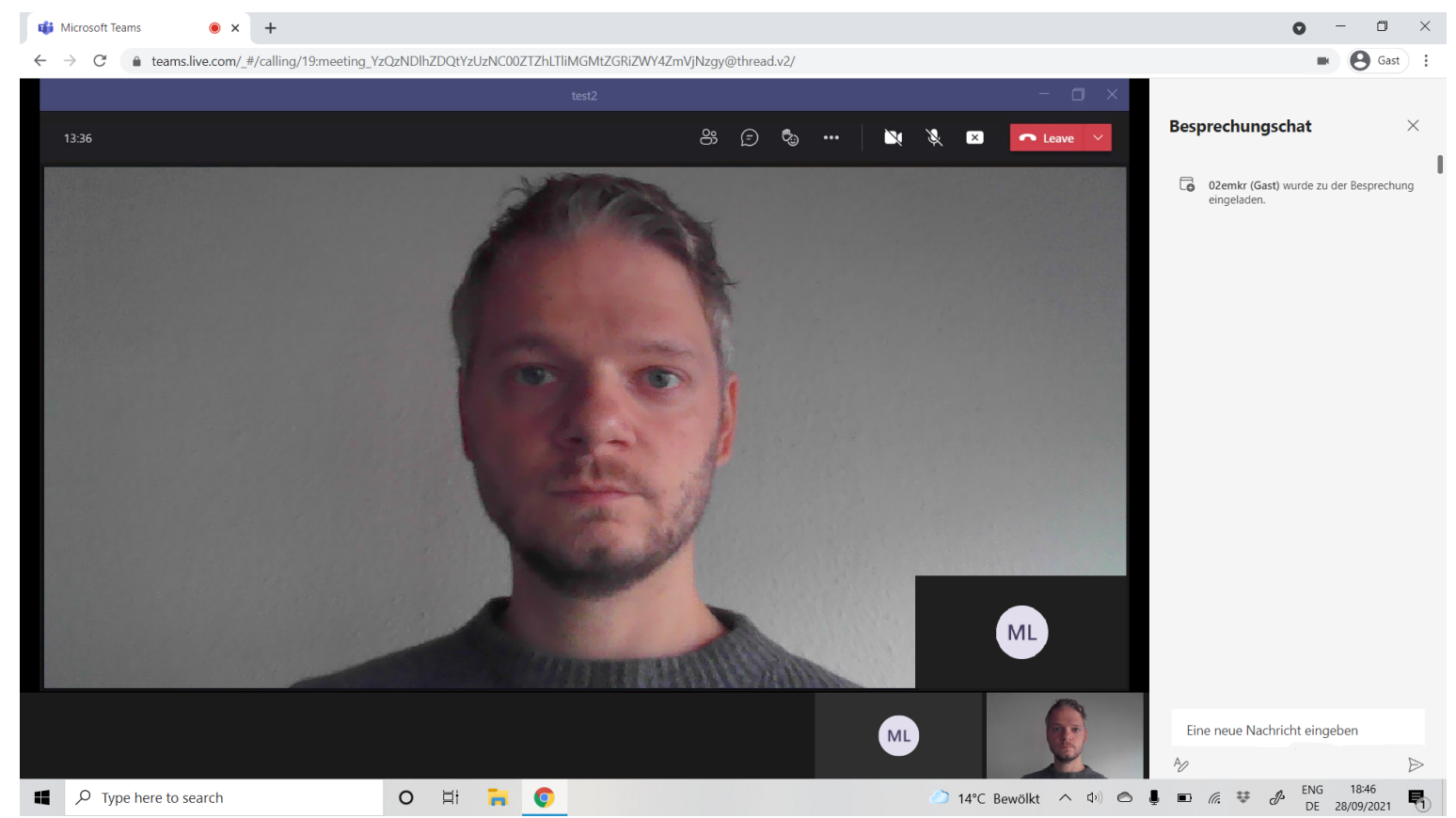

Figure A6: Decision screen in Self-Call

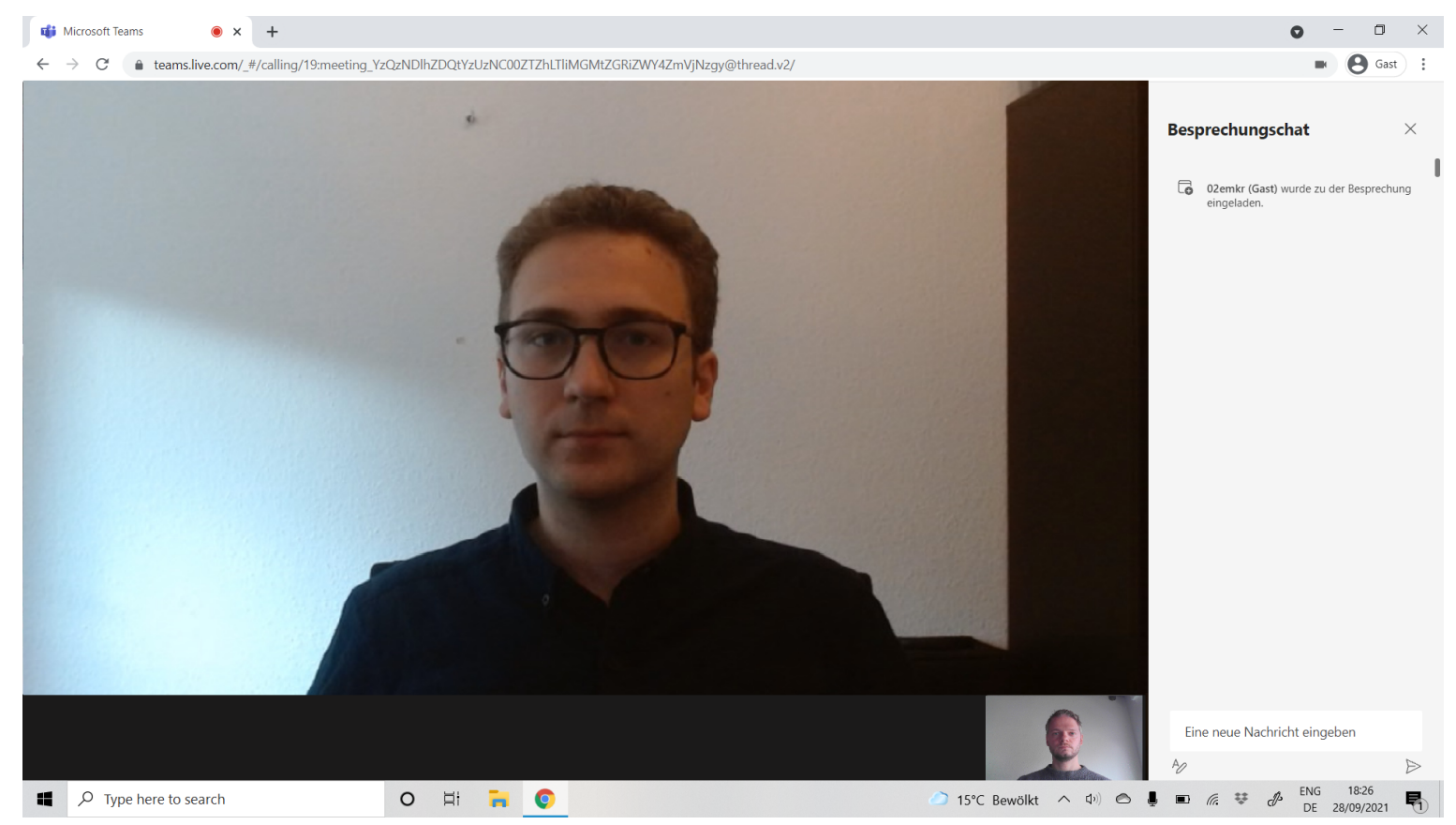

Figure A7: Decision screen in Social-Call 